\title{
A multi-state model approach for risk analysis of pensions for married couples with consideration of mortality difference by marital status
}

\author{
Anastasia Stefani $^{a}{ }$, Hyuk-Sung Kwon ${ }^{1, a}$ \\ ${ }^{a}$ Department of Statistics and Actuarial Science, Soongsil University, Korea
}

\begin{abstract}
Marital status has been identified as an important risk factor affecting adult mortality. Many studies have found that marriage has positive effects on mortality and increases life expectancy. Since most pension contracts providing retirement income are provided to married couples, mortality assumption for actuarial valuation based on the entire population is likely to overestimate the actual mortality of the group of beneficiaries specified in the contracts. This study considered the differences in mortality according to marital status to analyze the length and value of the payments of a typical pension contract for a married couple. The study quantified the effect on actuarial measurements of considering marital status in mortality assumptions with a multi-state model framework using Korean experience mortality data organized by marital status. The results of analysis indicate that considering marital status in mortality assumptions improves mortality risk management.
\end{abstract}

Keywords: annuity, marital status, mortality, multi-state model, pension, risk factor

\section{Background}

Securing a certain income level to maintain quality of life after retirement is an important personal and social problem, as human life expectancy is increasing. Public pensions are a major source of retirement income providing monthly payments until the death of the beneficiary. Reverse mortgages and home pensions, which provide a certain amount of money each month until the contractor dies as collateral for the house, can provide additional retirement income to homeowners. Regular payments, which is called annuity in financial term, from public pensions and reverse mortgages are generally made to married couples until both parties are dead.

A life table indicating the probability of death at each age divided by sex is used to determine the amount of regular payments in annuity-type contracts such as pensions and reverse mortgages; other variables, such as interest rate and salary level, are also considered in an actuarial model. It is implicitly assumed that age and sex are the only variables that affect mortality. However, many studies have found that additional factors other than age and sex are significantly associated with human mortality. These include socio-economic/demographic characteristics such as income level, education level, and marital status; health behavioral factors such as smoking, alcohol intake, and physical activity; and other factors such as religion and ethnicity.

Brown and McDaid (2003) summarized the risk factors affecting retirement mortality and suggested that they should be considered in the risk management of pensions and individual annuities;

\footnotetext{
${ }^{1}$ Corresponding author: Department of Statistics and Actuarial Science, Soongsil University, 369, Sangdo-ro, Dongjakgu, Seoul 06978, Korea. E-mail: hskwon@ssu.ac.kr
}

Published 30 November 2021 / journal homepage: http://csam.or.kr

(C) 2021 The Korean Statistical Society, and Korean International Statistical Society. All rights reserved. 
marital status was one of the important mortality risk factors. Since Gove (1973) explored mortality difference according to marital status and discussed how marriage lowers mortality, various experience studies have been conducted on the relationship between marital status and mortality.

In particular, marital status has been found to be an important demographic mortality risk factor. Many experience studies including Hu and Goldman (1990), Murphy et al. (2007), Kwon and Kim (2013), Pechholdova and Samanova (2013), and Jia and Lubetkin (2020) have investigated mortality differences among groups classified by marital status. These studies typically considered four marital status groups: married, single, widowed, and divorced. Most studies have found that married people have longer life expectancies than do people in other marital status groups and that the life expectancy benefits of marriage are greater for males than for females.

One group of studies focused on the relationship between marital status and morbidity associated with adult diseases. Trovato and Lauris (1989) analyzed Canadian data on mortality due to cancer and cardiovascular disease and found benefits to marriage in the cause-specific mortality they examined. In addition, Ramezankhani et al. (2019) used Iranian cohort data to explore the relationship between marital status and several diseases such as diabetes, hypertension, and heart diseases.

Kposowa (2000) and Park et al. (2018) found that mortality rates due to suicide differed according to marital status. Gomez et al. (2016) investigated cohort data in the United States to observe the impact of marital status on the survival of cancer patients finding that the higher survival rate of married people could be partially explained by economic factors. Martinez et al. (2016) found that the differences in survival rates among cancer patients according to marital status differed by ethnicity. The authors also found that the relationship between marital status and incidence of disease varied by gender.

Other studies have explored how the relationship between marital status and mortality is mediated by other factors. Hedel et al. (2015) studied mortality data in seven countries and found that the advantage of marriage depended on the person's labor force activity. Smith and Waitzman (1994) used U.S. panel data to find an interaction between marital status and poverty status affecting mortality. Lee (2012) analyzed the relationship between marital status and mortality according to health condition using mortality data on retired people in Korea, finding that the mortality difference was not significant among healthy people. Lillard and Panis (1996) discussed the role of health status to explain the mortality benefits of marriage based on longitudinal U.S. data.

Brockmann and Klein (2004) addressed the effect of biography (in terms of marital status) on mortality based on an analysis of longitudinal German data. Whisman et al. (2018) explored the relationship between satisfaction with married life and longevity by gender. The authors' analysis of U.S. panel data found that the advantage of marriage for longevity depended on the degree of satisfaction with married life. Bulanda et al. (2016) considered both satisfaction with married life and change in marital status in their mortality study based on U.S. panel data, finding that satisfaction with married life mediated the effect of change in marital status on mortality.

Frees et al. (1996) discussed a dependent mortality model, which is called copula, to quantify annuity values of dependent lives such as married couples. The authors found that there was strong positive dependence between dependent lives and that annuity values were reduced comparing with a model assuming independence. Kwon and Jones (2006) constructed a model based on Canadian sample data that accommodated risk factors such as marital status and potential changes to them in order to quantify the differences in the value of annuities among groups classified by the risk factors considered. Kwon (2015) analyzed Korean population data to quantify the annuity values for various risk groups classified by marital status. Alaminos and Ayuso (2019) analyzed Spanish data on people aged over 65 to examine the differences in mortality and annuity values between married 
and unmarried women. The authors found that unmarried women were more likely to be exposed to the risk of having insufficient retirement income than were married women and that social policy measures were necessary to address their finding.

Since the beneficiaries of annuity-type contracts have various marital statuses, uncertainty associated with mortality can be evaluated separately for various risk groups classified by marital status if the required information is available. If a married couple are pension beneficiaries, the expected payment period derived from a life table based only on age and sex is likely to underestimate the actual payment period since married people have a longer life expectancy than do people with other marital statuses owing to the economic and social benefits of marriage. This underestimation can damage the financial soundness of pension funds since total payment amount is likely to be larger than expected.

This study intends to quantify the expected pension payment period for married couples by constructing life tables organized by marital status. Since the beneficiaries consist of two individuals, a multiple life function called "last survivor status" is used. Furthermore, as the death of either person in a married couple changes the marital status of the remaining spouse, an appropriate model allowing for this change of marital status should be considered. The results of this study are expected to provide practical implications for the mortality risk management of pensions and reverse mortgages.

The rest of this paper is organized as follows. The literature on the relationship between marital status and mortality is briefly reviewed in Section 2. Experience mortality rates by marital status and the data used for this study are described in Section 3. A detailed explanation of the construction of the study's mortality model for married couples is presented in Section 4. Section 5 discusses the calculation of expected pension payment periods based on the proposed model and its implications for the mortality risk management of pensions and reverse mortgages. Finally, the paper closes with concluding remarks in Section 6.

\section{Data}

Statistics Korea provides a variety of demographic data through the Korean Statistical Information Service (KOSIS) and the Microdata Integrated Service (MDIS). Population data by age, gender, and marital status are available from 1925 to 2015; these are obtained from Korea's Population and Housing Census, which has been conducted every five years. Data on the numbers of deaths by age, gender, and marital status from 1997 to 2019 can also be obtained. In both the population and deaths data, marital status comprises four categories: "single," "married," "divorced," and "widowed."

Therefore, mortality rates by marital status, categorized by age and gender, can be calculated for 2005, 2010, and 2015. Tables 1 and 2 summarized the population and the number of deaths by marital status for age groups. Figure 1 illustrates the proportions of the Korean population by marital status. As expected, the relative proportion of married and widowed people by age differ by gender due to the mortality gap between males and females. Although the overall shapes of the graphs look similar for each gender, some noticeable differences can be observed. Observing the proportions for those in their early 30 s by year reveals that the average age of marriage has increased over time.

In addition, the proportion of single people has increased as well, which has contributed to Korea's low fertility rate in recent years. It can be also observed that the divorce rate has increased. As the proportion of married people aged around 60 is much higher than that of other marital status groups, most of those who begin receiving pension benefits or who enter reverse mortgages are mostly married.

Figure 2 presents crude mortality rates by marital status from age 30 to 84 . As is in the previous studies, we find distinct mortality differences between the four marital status groups. The mortality 
Table 1: Population by marital status

\begin{tabular}{|c|c|c|c|c|c|c|c|c|c|}
\hline & & \multicolumn{4}{|c|}{ Male } & \multicolumn{4}{|c|}{ Female } \\
\hline Year & Ages & Single & Married & Divorced & Widowed & Single & Married & Divorced & Widowed \\
\hline \multirow{6}{*}{2005} & $30-39$ & $1,229,605$ & $2,790,443$ & 97,421 & 8,112 & 543,426 & $3,370,772$ & 141,725 & 27,563 \\
\hline & $40-49$ & 264,347 & $3,513,248$ & 228,921 & 37,770 & 120,087 & $3,427,558$ & 273,553 & 158,456 \\
\hline & $50-59$ & 48,787 & $2,298,807$ & 138,429 & 67,571 & 36,268 & $2,046,823$ & 135,138 & 361,912 \\
\hline & $60-69$ & 11,521 & $1,494,147$ & 41,896 & 105,769 & 12,812 & $1,176,504$ & 39,912 & 686,359 \\
\hline & $70-79$ & 2,964 & 665,578 & 7,590 & 108,741 & 5,781 & 392,239 & 10,553 & 826,158 \\
\hline & $80-84$ & 502 & 98,174 & 697 & 37,332 & 1,550 & 32,117 & 1,534 & 260,353 \\
\hline \multirow{6}{*}{2010} & $30-39$ & $1,489,578$ & $2,350,237$ & 86,259 & 5,242 & 790,162 & $2,917,760$ & 144,611 & 17,903 \\
\hline & $40-49$ & 453,957 & $3,367,774$ & 276,936 & 30,026 & 195,259 & $3,423,950$ & 356,916 & 117,455 \\
\hline & $50-59$ & 111,238 & $2,833,579$ & 250,797 & 74,138 & 69,583 & $2,631,893$ & 272,929 & 348,852 \\
\hline & $60-69$ & 20,896 & $1,697,660$ & 89,440 & 110,029 & 21,782 & $1,379,277$ & 81,260 & 633,732 \\
\hline & $70-79$ & 5,342 & 958,459 & 20,498 & 139,682 & 10,055 & 620,593 & 20,882 & 944,303 \\
\hline & $80-84$ & 741 & 150,396 & 1,649 & 48,653 & 2,846 & 61,738 & 2,775 & 363,068 \\
\hline \multirow{6}{*}{2015} & $30-39$ & $1,667,542$ & $2,038,651$ & 63,381 & 3,597 & $1,014,429$ & $2,471,460$ & 112,034 & 10,931 \\
\hline & $40-49$ & 779,122 & $3,199,458$ & 281,287 & 21,111 & 369,618 & $3,321,181$ & 411,382 & 84,175 \\
\hline & $50-59$ & 257,006 & $3,307,007$ & 380,794 & 68,733 & 130,958 & $3,062,057$ & 456,229 & 335,980 \\
\hline & $60-69$ & 51,165 & $2,025,917$ & 173,654 & 105,810 & 47,703 & $1,654,133$ & 174,338 & 628,480 \\
\hline & $70-79$ & 11,330 & $1,131,077$ & 49,819 & 145,458 & 18,674 & 728,345 & 49,593 & 974,899 \\
\hline & $80-84$ & 1,436 & 211,297 & 4,504 & 55,597 & 5,009 & 99,063 & 6,456 & 422,211 \\
\hline
\end{tabular}

Table 2: Number of deaths by marital status

\begin{tabular}{|c|c|c|c|c|c|c|c|c|c|}
\hline \multirow{2}{*}{ Year } & \multirow[b]{2}{*}{ Ages } & \multicolumn{4}{|c|}{ Male } & \multicolumn{4}{|c|}{ Female } \\
\hline & & Single & Married & Divorced & Widowed & Single & Married & Divorced & Widowed \\
\hline \multirow{6}{*}{2005} & $30-39$ & 2,741 & 2,271 & 551 & 54 & 645 & 1,737 & 350 & 61 \\
\hline & $40-49$ & 2,925 & 8,655 & 2,539 & 283 & 413 & 3,567 & 855 & 370 \\
\hline & $50-59$ & 1,267 & 14,235 & 2,652 & 765 & 308 & 4,454 & 682 & 1,240 \\
\hline & $60-69$ & 629 & 26,089 & 1,643 & 2,683 & 386 & 7,142 & 550 & 6,164 \\
\hline & $70-79$ & 310 & 26,264 & 570 & 5,895 & 623 & 6,516 & 529 & 21,917 \\
\hline & $80-84$ & 87 & 8,953 & 142 & 4,364 & 303 & 1,728 & 225 & 17,251 \\
\hline \multirow{6}{*}{2010} & $30-39$ & 2,633 & 1,570 & 454 & 29 & 851 & 1,356 & 336 & 28 \\
\hline & $40-49$ & 3,325 & 6,595 & 2,508 & 193 & 508 & 3,161 & 941 & 261 \\
\hline & $50-59$ & 2,155 & 13,986 & 4,320 & 571 & 399 & 4,643 & 1,102 & 1,007 \\
\hline & $60-69$ & 783 & 22,340 & 2,879 & 1,746 & 347 & 6,347 & 832 & 4,398 \\
\hline & $70-79$ & 405 & 32,542 & 1,377 & 6,037 & 714 & 8,165 & 665 & 19,528 \\
\hline & $80-84$ & 98 & 10,985 & 223 & 4,125 & 402 & 2,280 & 269 & 17,975 \\
\hline \multirow{6}{*}{2015} & $30-39$ & 2,155 & 977 & 236 & 12 & 880 & 889 & 232 & 18 \\
\hline & $40-49$ & 3,401 & 4,357 & 1,935 & 105 & 635 & 2,628 & 858 & 153 \\
\hline & $50-59$ & 3,167 & 12,162 & 5,323 & 580 & 430 & 4,749 & 1,360 & 804 \\
\hline & $60-69$ & 1,256 & 19,269 & 4,321 & 1,405 & 394 & 5,760 & 1,093 & 2,978 \\
\hline & $70-79$ & 482 & 35,150 & 2,809 & 5,811 & 655 & 9,587 & 1,027 & 17,438 \\
\hline & $80-84$ & 122 & 15,252 & 541 & 4,969 & 537 & 3,574 & 446 & 19,513 \\
\hline
\end{tabular}

rates used to determine pension, annuity, or reverse mortgage benefits are derived using experience mortality data drawn from the Korean population as a whole. As marital status has been found to be a significant risk factor for mortality, the risk associated with mortality can be evaluated more accurately if the mortality differences according to marital status are considered.

Mortality differences are observed at younger ages in males than in females. However, the differences between the four marital status groups are more distinct for females. Since the married and widowed groups show lower mortality levels, the mortality assumption based on the entire population likely overestimates the mortality levels among groups of annuitants since most are married or widowed, as indicated in Figure 1. This underestimation can be expanded to include annuities for married couples since annuity payments are made until both spouses die. 

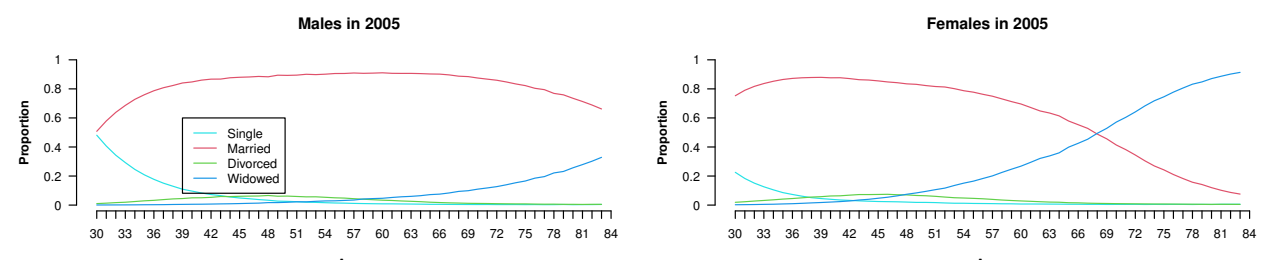

Age
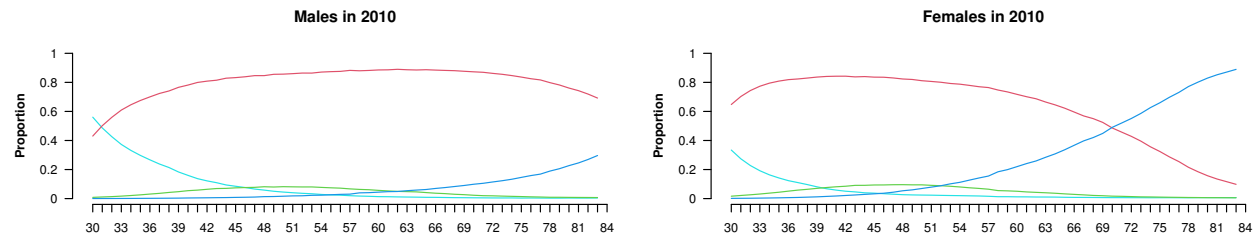

Age

Age
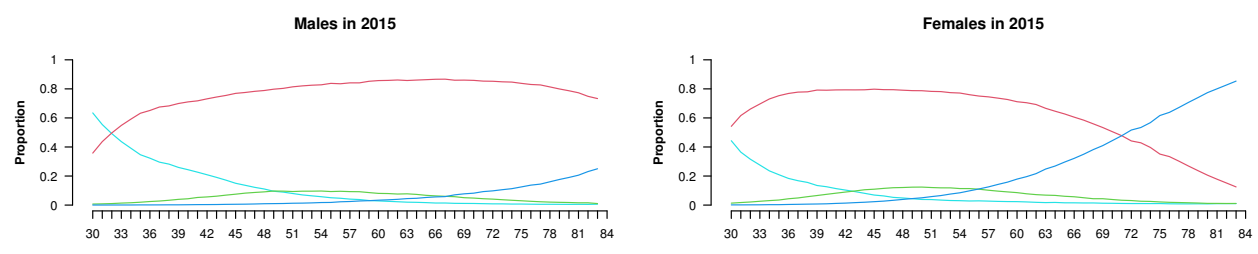

Age

Age

Figure 1: Proportions of population by marital status in Korea.

Therefore, this study constructs a mortality model for the lifetime of married couples that reflects mortality differences by marital status and also allows for changes in marital status due to the death of the spouse. The model can be used to quantify how an expected annuity payment period for a married couple reflecting mortality differences by marital status deviates from the case where only the mortality of the entire population is considered. This is discussed in the following sections.

\section{Construction of a model for the lifetime of married couples}

Normally, annuity-type contracts such as a pension or reverse mortgage for married couples provides continued benefits to a spouse who becomes bereaved. As annuity benefits are usually made until both partners in a married couple die, a multiple life function called "last survivor status" can be used to measure how long annuity payments will be made. In this function, the future lifetime of two persons aged $x$ and $y$, denoted by $T_{\overline{x y}}$, is defined as $T_{\overline{x y}}=\max \left(T_{x}, T_{y}\right)$, where $T_{x}$ and $T_{y}$ are random variables representing the future lifetimes of the person aged $x$ and the person aged $y$, respectively. Therefore, $T_{\overline{x y}}$ is the length of lifetime of a spouse who will live longer than his/her spouse that is identical to the length of time during which annuity benefits for the married couple will be available in the future.

Consider a married couple comprising a man aged $x$ and a woman aged $y$, who start to receive annuity benefits payable at the beginning of every year while either of them is alive. The mortality of married people applies when both parties in the married couple are alive. However, after one of them dies, the mortality of widowed people should apply for the bereaved partner. Thus, the possibility of a change in marital status due to the death of the spouse should be reflected when mortality difference is considered in a model.

A multi-state model allows us to define various states indicating the survivorship of a married 

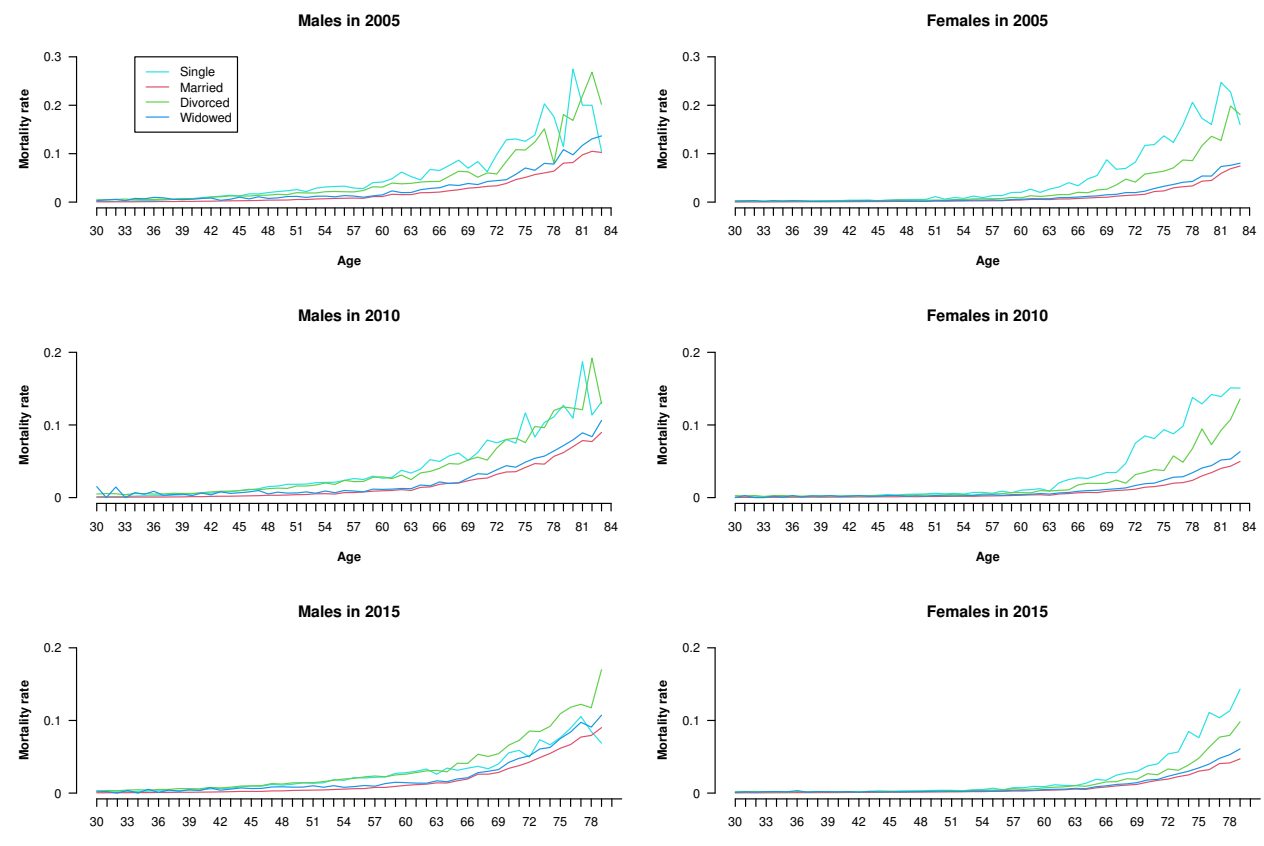

Age

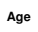

Figure 2: Mortality rates by marital status in Korea.

couple so that the appropriate mortality rates according to marital status and indicated by a state can be applied. The possibility of a change in state due to the death of a man or a woman can also be modeled as a transition probability. The possibility of divorce is not considered in this study since continued benefits for bereaved spouses is not available if the married couple has divorced. Therefore, a multi-state model consisting of the following four states was considered for a married couple:

- State 1: Both are alive

- State 2: Only the woman spouse is alive

- State 3: Only the man spouse is alive

- State 4: Both are dead

The structure of the multi-state model used in this study based on the defined states is illustrated in Figure 3, in which the possible transitions between the two states are indicated by arrows. Annuity contracts for a married couple start from State 1. While both partners of the married couple are alive, the mortality of married people applies. We denote the probability of death within one year for a male and a female of the couple at age $k$ by $q_{k}^{C M}$ and $q_{k}^{C F}$, respectively. After a change to State 2 or State 3 due to the death of the spouse, the mortality of widowed people applies. We denote the probability of death within one year for the widowed male and widowed female at age $\mathrm{k}$ by $q_{k}^{W M}$ and $q_{k}^{W F}$, respectively. Finally, a transition from any of State 1 , State 2, or State 3 to State 4 indicates the end of annuity payments.

Since the annual mortality rate for each integer age by marital status is available for this study, a discrete time multi-state model can be applied. The model is specified with a transition matrix that 


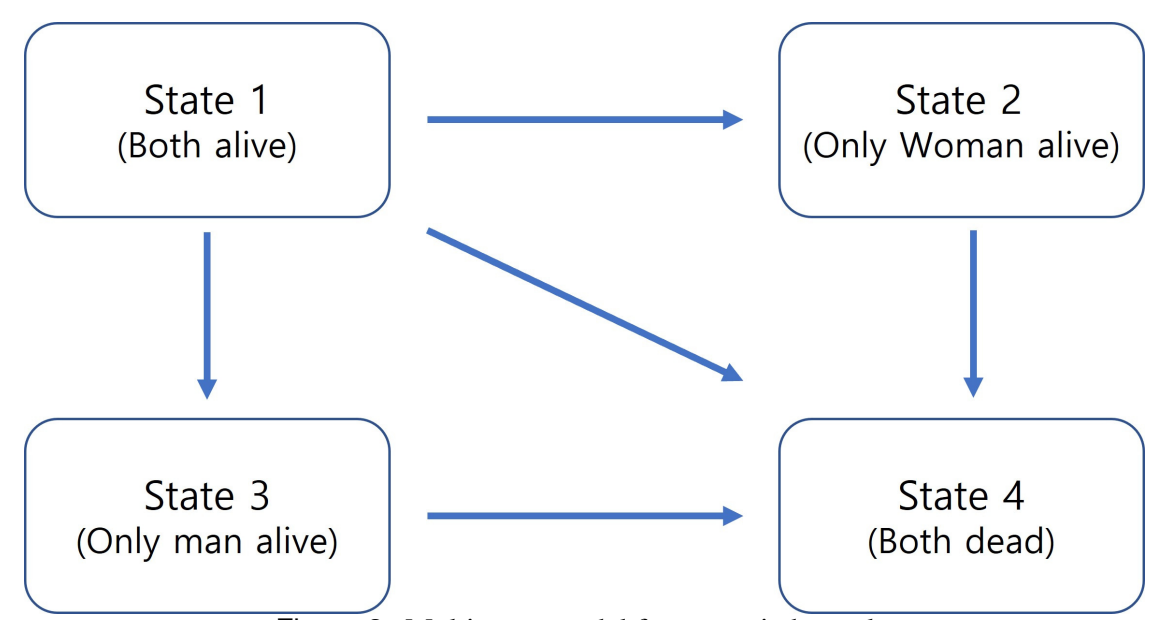

Figure 3: Multi-state model for a married couple.

includes the one-year probability of a transition from any state to another. As the ages of the married couple increase over time until death, the transition matrix varies according to the age of the annuity contract. As shown in Figure 3, five types of transitions are possible in each policy year of the annuity contract. We let $q_{i j}(m)$ be the transition probability from State $i$ to State $j$ in policy year $m$. Then, assuming that the mortality of each partner of the married couple is independent, the five transition probabilities can be expressed as follows,

$$
\begin{aligned}
& q_{12}(m)=q_{x+m-1}^{C M} \cdot\left(1-q_{y+m-1}^{C F}\right) \\
& q_{13}(m)=\left(1-q_{x+m-1}^{C M}\right) \cdot q_{y+m-1}^{C F} \\
& q_{14}(m)=q_{x+m-1}^{C M} \cdot q_{y+m-1}^{C F} \\
& q_{24}(m)=q_{y+m-1}^{W F} \\
& q_{34}(m)=q_{x+m-1}^{W M}
\end{aligned}
$$

Based on the transition probabilities obtained in Equation (3.1), the transition matrix for policy year $m$, denoted by $Q_{m}$, is expressed as,

$$
Q_{m}=\left[\begin{array}{cccc}
1-q_{12}(m)-q_{13}(m)-q_{14}(m) & q_{12}(m) & q_{13}(m) & q_{14}(m) \\
0 & 1-q_{24}(m) & 0 & q_{24}(m) \\
0 & 0 & 1-q_{34}(m) & q_{34}(m) \\
0 & 0 & 0 & 1
\end{array}\right]
$$

Calculating the transition probabilities in equation (3.1) requires the mortality rates by marital status. The crude mortality rates shown in Figure 2 do not present a strict age-increasing pattern due to the small amount of data used, especially for older ages. Thus, the rates should be smoothed by an appropriate graduation method to obtain mortality values that increase strictly by age. Using 2015 data, the crude mortality rates of married and widowed groups are smoothed via Greville's 13term graduation, which has been widely used to smooth mortality data in actuarial practice in Korea. (The method's theoretical background and implementation are discussed in Park et al. (2009).) The graduated mortality rates are shown in Figure 4. In order to observe how sensitive the results of anal- 

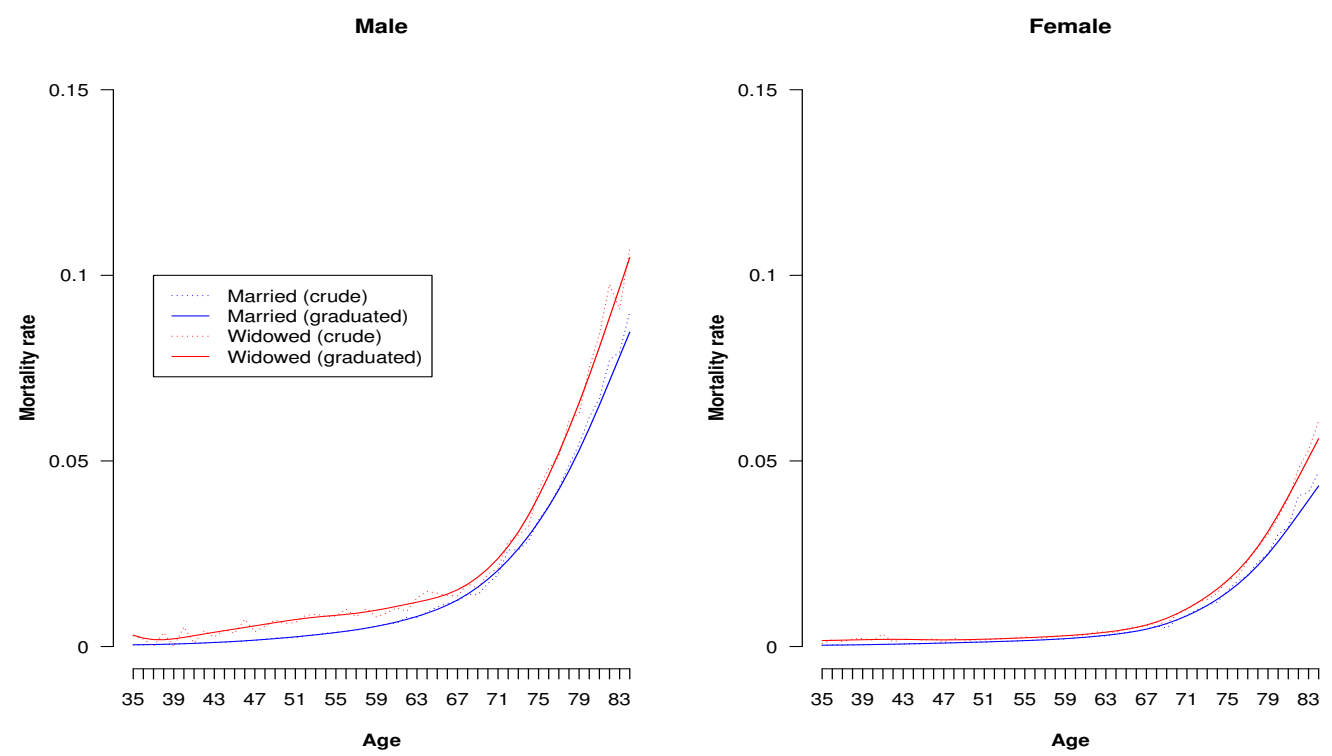

Figure 4: Graduated mortality rates using Greville's method.

ysis according to graduation method, the appendix presents the results obtained using the WhittakerHenderson graduation method, which is discussed in Lowrie (1982).

\section{Implications for risk management of annuities for married couples}

The approach based on the multi-state model allows for a more detailed actuarial analysis when the payment conditions of an annuity depend on the status of the annuitants. In most of public pension contracts for married couples, the amount of regular annuity payments generally depends on the survival status of the two spouses. Therefore, the multi-state model allows the future cash flows of an annuity for a married couple to be analyzed more comprehensively.

First, the expected payment period of an annuity is investigated. The payment period can be divided into two cases within the framework of the multi-state model described in the previous section. One is the period in which both spouses in a married couple are alive, corresponding to State 1; here, the full annuity payment is made. The other case is the period in which only one spouse is alive, corresponding to States 2 and 3; here, a reduced amount is paid. Since mortality rates are available up to age 84, the maximum year of observation should be considered. Following Dickson et al. (2020), the $n$-year temporary life expectancy of a person age $x$, which is the expected future lifetime of a person currently aged $x$ with $n$-year limit, is defined as $E\left[\min \left(T_{x}, n\right)\right]$, which is calculated by,

$$
E\left[\min \left(T_{x}, n\right)\right]=\sum_{k=1}^{n}{ }_{k} p_{x}
$$

where ${ }_{k} p_{x}$ is the probability that the person currently aged $\mathrm{x}$ will be still alive at age $x+k$. For integer value $k,{ }_{k} p_{x}$ is obtained by $\prod_{j=0}^{k-1}\left(1-q_{x+j}\right)$ where $q_{x+j}$ is the probability of death within a year of a 
survivor aged $x+j$. Also, the corresponding second moment is expressed as,

$$
E\left[\min \left(T_{x}, n\right)^{2}\right]=\sum_{k=1}^{n}(2 k-1)_{k} p_{x}
$$

In order to extend equations (4.1) and (4.2) for multi-state model being considered, the survival probability ${ }_{k} p_{x}$ should be replaced by the probability that last survivor status is still alive, which is equivalent to being in State 1, 2, or $3 k$ years later from the beginning of the contract. Since the contract starts with State 1 , the probability can be obtained by the sum of $(1,1),(1,2)$, and $(1,3)$ elements of $k$-step transition matrix. Therefore, the expected payment period until both spouses of the married couple die with a maximum of $n$ years and a corresponding second moment can be expressed as,

$$
\begin{array}{r}
\sum_{k=1}^{n} \sum_{j=1}^{3} P_{k}(1, j), \\
\sum_{k=1}^{n}(2 k-1) \sum_{j=1}^{3} P_{k}(1, j)
\end{array}
$$

where $P_{k}$ is defined as the matrix multiplication $Q_{1} Q_{2} Q_{3}, \ldots, Q_{k}$, and $P_{k}(i, j)$ is the $(i, j)$ element of the matrix $P_{k}$. Equation (4.3) can be modified to calculate the expected payment period in which both partners of the married couple are alive with a maximum of $n$ years and a corresponding second moment as follows (In this case, only staying in State 1 is considered),

$$
\begin{array}{r}
\sum_{k=1}^{n} P_{k}(1,1), \\
\sum_{k=1}^{n}(2 k-1) \cdot P_{k}(1,1)
\end{array}
$$

If mortality differences by marital status aren't considered, equations (4.3) and (4.4) are still applied after modifying the transition matrix in equation (3.2) by replacing $q_{k+m-1}^{C M}$ and $q_{k+m-1}^{W M}$ by $q_{k+m-1}^{P M}$, and by replacing $q_{k+m-1}^{C F}$ and $q_{k+m-1}^{W F}$ by $q_{k+m-1}^{P F}$ in expressions in equation (3.1), where $q_{k+m-1}^{P M}$ and $q_{k+m-1}^{P F}$ are the mortalities of the entire population of males and females, respectively. As the mortality table goes up only to age 84 , the maximum survival period of the married couple, which is expressed as $n$ in equations (4.3) and (4.4), is set to 30 years. The expected payment periods derived then marital status is considered for various combinations of married couple ages are presented in Table 3. For comparison, the corresponding results based on the mortality of the entire population are shown in Table 4.

Comparing Tables 3 and 4 reveals that the lengths of the period in which the couple stay in State 1,2 , or 3 are very similar. In the beginning, the lower mortality of the married couple relative to the general population results in a longer State 1 period. After one of the spouses dies, the mortality of widowed people which is higher than that of the general population applies to the bereaved spouse. This results in a shorter State 2 or State 3 period. As a result, the total expected length of the State 1, 2 , or 3 period becomes similar. However, the length of period for State 1 differs depending on the age of the married couple.

This result can be illustrated in terms of the probabilities of staying in a certain set of states by elapsed year in the two cases depending on whether marital status is reflected in the mortality; this is 
Table 3: Expected payment periods (consideration of mortality difference)

\begin{tabular}{cccccc}
\hline \hline \multicolumn{2}{c}{ Age } & \multicolumn{2}{c}{ In State 1-3 } & \multicolumn{2}{c}{ In State 1 } \\
\hline Male & Female & Expected value & Standard deviation & Expected value & Standard deviation \\
\hline 55 & 52 & 29.20 & 2.51 & 23.24 & 7.62 \\
55 & 53 & 29.11 & 2.63 & 23.10 & 7.64 \\
55 & 54 & 29.00 & 2.76 & 22.95 & 7.65 \\
55 & 55 & 28.89 & 2.90 & 22.77 & 7.67 \\
54 & 55 & 28.97 & 2.79 & 23.18 & 7.59 \\
53 & 55 & 29.06 & 2.68 & 23.55 & 7.50 \\
52 & 55 & 29.14 & 2.58 & 23.90 & 7.40 \\
\hline \hline
\end{tabular}

Table 4: Expected payment periods (without consideration of mortality difference)

\begin{tabular}{cccccc}
\hline \hline \multicolumn{2}{c}{ Age } & \multicolumn{2}{c}{ In State 1-3 } & \multicolumn{2}{c}{ In State 1 } \\
\hline Male & Female & Expected value & Standard deviation & Expected value & Standard deviation \\
\hline 55 & 52 & 29.19 & 2.53 & 22.68 & 7.87 \\
55 & 53 & 29.09 & 2.66 & 22.52 & 7.88 \\
55 & 54 & 28.98 & 2.79 & 22.35 & 7.88 \\
55 & 55 & 28.86 & 2.93 & 22.15 & 7.88 \\
54 & 55 & 28.95 & 2.82 & 22.55 & 7.82 \\
53 & 55 & 29.03 & 2.72 & 22.92 & 7.75 \\
52 & 55 & 29.11 & 2.61 & 23.26 & 7.68 \\
\hline \hline
\end{tabular}

presented in Figure 4. As expected from the previous discussion, the gap between the probabilities of staying in State 1, 2 or, 3 by elapsed year is small, although the gap increases over time. However, the gap of probabilities staying in the State 1 is distinct and increases over time.

The difference observed in Table 2 affects the value of an annuity for married couples. Consider a typical $n$-year life annuity contract for a married couple with an annuitant aged $x$ and his/her spouse aged $y$ for which 1 is paid while the annuitant is alive and $\alpha$ is paid to the bereaved spouse after the annuitant dies. Assume that the person aged $x$ is a male and the person aged $y$ is a female and that the payment is made at the beginning of each year.

The present value of the annuity paid to the married couple depends on the future lifetimes of the two spouses. Let $K_{x}$ be the future lifetime in complete years of a survivor aged $x$. Then, two cases can be separately considered depending on whether reduced payment $\alpha$ is made or not. If the male lives longer than the female or if the male survives the time point of last annuity payment, reduced payment is never paid. On the other hand, if the female lives longer than the male by more than one year, reduced payment is made to the female. In this case, full annuity payment of 1 is made $K_{x+1}$ times and reduced payment $\alpha$ follows. The number of reduced payments is $K_{y}-K_{x}$, which is limited to $n-K_{x}-1$. Therefore, considering the time value of the series of annuity payments, the present values of the annuity are expressed as follows,

$$
\begin{cases}\sum_{k=0}^{\min \left(k_{x}, n-1\right)}(1+i)^{-k}, & K_{x} \geq K_{y} \text { or } K_{x} \geq n-1, \\ \sum_{k=0}^{K_{x}}(1+i)^{-k}+\alpha \cdot(1+i)^{-K_{x}-1} \cdot \sum_{k=0}^{\min \left(K_{y}-K_{x}-1, n-K_{x}-2\right)}(1+i)^{-k}, & K_{x}+1 \leq K_{y}, K_{x}<n-1,\end{cases}
$$

where $i$ is the annual interest rate. To calculate the actuarial present value of the annuity, which is 
the expected value of the present values, the joint probabilities of $K_{x}$ and $K_{y}$ should be determined. If marital status is considered in mortality, then the joint probabilities can be express as,

$$
\begin{aligned}
& P\left(K_{x}=h, K_{y}=k\right)= \begin{cases}q_{x}^{C M} \cdot q_{y}^{C F} & h=k=0, \\
q_{x}^{C M} \cdot\left(1-q_{y}^{C F}\right){ }_{k-1} p_{y+1}^{W F} \cdot q_{y+k}^{W F} & h=0,0<k<n-1, \\
\left(1-q_{x}^{C M}\right) \cdot{ }_{h-1} p_{x+1}^{W M} \cdot q_{x+h}^{W M} \cdot q_{y}^{C F} & k=0,0<h<n-1, \\
{ }_{h} p_{x}^{C M} \cdot q_{x+h}^{C M} \cdot{ }_{k} p_{y}^{C F} \cdot q_{y+k}^{C F} & 0<h=k<n-1, \\
{ }_{h} p_{x}^{C M} \cdot q_{x+h}^{C M} \cdot{ }_{h+1} p_{y}^{C F} \cdot{ }_{k-h-1} p_{y+h+1}^{W F} \cdot q_{y+k}^{W F} & 0<h<k<n-1, \\
{ }_{k+1} p_{x}^{C M} \cdot{ }_{h-k-1} p_{x+k+1}^{W M} \cdot q_{x+h}^{W M} \cdot{ }_{k} p_{y}^{C F} \cdot q_{y+k}^{C F} & 0<k<h<n-1,\end{cases} \\
& P\left(K_{x}=h, K_{y}=n-1\right)={ }_{h} p_{x}^{C M} \cdot q_{x+h}^{C M} \cdot{ }_{h+1} p_{y}^{C F} \cdot{ }_{n-h-2} p_{y+h+1}^{W F}, \quad(h<n-1) \\
& P\left(K_{x} \geq n-1, K_{y}=k\right)={ }_{k+1} p_{x}^{C M} \cdot{ }_{n-k-2} p_{x+k+1}^{W M} \cdot{ }_{k} p_{y}^{C F} \cdot q_{y+k}^{C F}, \quad(k<n-1) \\
& P\left(K_{x} \geq n-1, K_{y} \geq n-1\right)=1-\sum_{h=1}^{n-2} \sum_{k=1}^{n-2} P\left(K_{x}=h, K_{y}=k\right) \\
& -\sum_{h=1}^{n-2} P\left(K_{x}=h, K_{y} \geq n-1\right) \\
& -\sum_{k=1}^{n=2} P\left(K_{x} \geq n-1, K_{y}=k\right)
\end{aligned}
$$

Since mortality rates separated by marital status are being used, appropriate mortality rates depending on the survivorship of spouses should be applied. When both spouses die before the last annuity payment is made and $K_{x}=K_{y}$, only mortality rates for the married are applied until death of both spouses. The joint probability for these cases is the product $P\left(K_{x}=h\right) P\left(K_{y}=k\right)$ by applying only mortality rates for the married, which corresponds to the first and fourth expressions in equation (4.6). However, mortality rates for the widowed needs to be applied to the remaining spouse after a spouse dies.

For the case of $K_{x}<K_{y}, P\left(K_{x}=h\right)$ can still be obtained using only mortality rates for the married. Since the female becomes widowed, the survival probability for the first $h+1$ years is calculated by mortality rates for the married and the mortality rates for the widowed are applied thereafter, which corresponds to the second and the fifth expressions in equation (4.6). Likewise, the third and the last expressions in equation (4.6) are obtained for the case of $K_{x}>K_{y}$. Equations (4.7) and (4.8) are obtained by similar methods to the case of $K_{x}<K_{y}$ and $K_{x}>K_{y}$ in equation (4.6), respectively, except that the female survives up to the time of the last annuity payment. Finally, equation (4.9) is necessary so that all joint probabilities sum up to 1 .

The superscripts in the notations for the probabilities of survival and death in equations (4.6) to (4.8) indicate that the probability is calculated based on the mortality rates of a certain marital status, where the meanings of the superscripts are defined in Section 4. Based on the probabilities obtained from equations (4.6) to (4.9), the expected value and standard deviation of the present values in equation (4.5) can be calculated for a 30-year annuity assuming the annual interest rate is $2 \%, 3 \%$, and $4 \%$ and $\alpha=0.6$ for various combinations of married couple ages. In this contract, two parties of the married couple are titled "annuitant" and his/her "spouse". When annuitant is alive, payment 1 is 
Table 5: Expected payment periods (without consideration of mortality difference)

\begin{tabular}{ccccccc}
\hline \hline Interest rate & Annuitant & Spouse & EPV & Standard deviation & EPV & Standard deviation \\
\hline & $55(\mathrm{M})$ & $52(\mathrm{~F})$ & 21.3061 & 2.3117 & 21.2034 & 2.3899 \\
& $55(\mathrm{M})$ & $53(\mathrm{~F})$ & 21.2767 & 2.3510 & 21.1743 & 2.4294 \\
& $55(\mathrm{M})$ & $54(\mathrm{~F})$ & 21.2437 & 2.3945 & 21.1415 & 2.4733 \\
$2 \%$ & $55(\mathrm{M})$ & $55(\mathrm{~F})$ & 21.2068 & 2.4424 & 21.1049 & 2.5217 \\
& $55(\mathrm{~F})$ & $52(\mathrm{M})$ & 21.9861 & 1.9780 & 21.9033 & 2.0330 \\
& $55(\mathrm{~F})$ & $53(\mathrm{M})$ & 21.9605 & 2.0225 & 21.8794 & 2.0774 \\
& $55(\mathrm{~F})$ & $54(\mathrm{M})$ & 21.9330 & 2.0699 & 21.8537 & 2.1243 \\
& $55(\mathrm{~F})$ & $55(\mathrm{M})$ & 21.9037 & 2.1201 & 21.8266 & 2.1734 \\
\hline & $55(\mathrm{M})$ & $52(\mathrm{~F})$ & 18.9449 & 1.9199 & 18.8584 & 1.9905 \\
& $55(\mathrm{M})$ & $53(\mathrm{~F})$ & 18.9219 & 1.9507 & 18.8356 & 2.0213 \\
& $55(\mathrm{M})$ & $54(\mathrm{~F})$ & 18.8961 & 1.9848 & 18.8099 & 2.0557 \\
& $55(\mathrm{M})$ & $55(\mathrm{~F})$ & 18.8672 & 2.0225 & 18.7812 & 2.0937 \\
& $55(\mathrm{~F})$ & $52(\mathrm{M})$ & 19.5014 & 1.6219 & 19.4343 & 1.6690 \\
& $55(\mathrm{~F})$ & $53(\mathrm{M})$ & 19.4813 & 1.6571 & 19.4155 & 1.7043 \\
& $55(\mathrm{~F})$ & $54(\mathrm{M})$ & 19.4598 & 1.6947 & 19.3954 & 1.7416 \\
& $55(\mathrm{~F})$ & $55(\mathrm{M})$ & 19.4367 & 1.7346 & 19.3740 & 1.7809 \\
\hline & $55(\mathrm{M})$ & $52(\mathrm{~F})$ & 16.9726 & 1.6075 & 16.8992 & 1.6714 \\
& $55(\mathrm{M})$ & $53(\mathrm{~F})$ & 16.9545 & 1.6316 & 16.8813 & 1.6956 \\
& $55(\mathrm{M})$ & $54(\mathrm{~F})$ & 16.9342 & 1.6585 & 16.8611 & 1.7227 \\
& $55(\mathrm{M})$ & $55(\mathrm{~F})$ & 16.9115 & 1.6883 & 16.8385 & 1.7526 \\
& $55(\mathrm{~F})$ & $52(\mathrm{M})$ & 17.4307 & 1.3403 & 17.3760 & 1.3809 \\
& $55(\mathrm{~F})$ & $53(\mathrm{M})$ & 17.4149 & 1.3682 & 17.3612 & 1.4091 \\
& $55(\mathrm{~F})$ & $54(\mathrm{M})$ & 17.3979 & 1.3981 & 17.3453 & 1.4390 \\
& $55(\mathrm{~F})$ & $55(\mathrm{M})$ & 17.3797 & 1.4300 & 17.3284 & 1.4705 \\
\hline \hline
\end{tabular}

made at the beginning of each year. If annuitant dies first, then spouse will receive reduced regular payment 0.6 until the spouse dies. The expected value and standard deviation based on the general population's mortality are also calculated to allow comparison with the case wherein marital status is not considered in mortality. The results are presented in Table 5. For a married couple with a male annuitant aged 55 and his spouse aged 52, the expected present values of the 30-year annuity when marital status is considered in mortality are $21.3061,18.9449$, and 16.9726 for an assumed annual interest rate of $2 \%, 3 \%$, and $4 \%$, respectively.

The corresponding expected present values based on the mortality of Korea's population as a whole are $21.2034,18.8584$, and 16.8992. This implies that the actual risk evaluated by considering marital status in mortality assumptions is nearly $0.5 \%$ higher than the result based on the population's mortality. This difference is considerable in the case of large public pensions such as special occupation (government employees, teachers, service person, etc.) The difference decreases as interest rates increase due to the effect of interest rate discounting. The Whittaker-Henderson graduation method produces similar results as the appendix shows.

The market of individual annuity products for married couple has been very small in Korea since insurers providing individual annuity products are reluctant to expand individual annuity market concerning longevity risk, interest rate risk, and possibly low profitability for multiple life pension. However, the importance of individual annuity for securing retirement income is addressed recently as the proportion of elderly population has been increasing fast.

According to the results of this study, there are implications on designing multiple life insurance or 
annuity products. When life annuity for married couple is considered, longevity risk should be carefully managed since population mortality table underestimate actual survival probabilities of married couple. From the perspective of annuitants, married couples have advantages for purchasing multiple life annuity products as they can expect longer benefit periods than assumed based on population mortality table. On the other hand, for life insurance product, which is usually purchased by married person for his/her spouse, mortality risk is reduced since population mortality table overestimate actual probability of death of married persons.

Mortality risk management is very important given the low interest rates in today's economic environment. Since the expected present values based on the mortality of the general population are lower than the values based on mortality when marital status is considered, the mortality risk management of annuity-type contracts is expected to improve when marital status is considered. The results also imply that an analysis based on a risk factor evaluates actual risk more accurately, offering useful insight into mortality risk management.

\section{Conclusion}

This study proposed a method of considering the differences in mortality by marital status to evaluate the value of annuity payments of a typical pension contract for married couples, who own the largest share of pension portfolios. A multi-state model was constructed based on graduated Korean experience mortality data that allows changes in the survival status of married couples, which are associated with annuity payment amounts. The expected payment periods depending on payment conditions and annuity values were analyzed.

The results from the proposed model were compared with the results obtained without considering mortality differences by marital status. The analysis revealed that the obligation for married pension beneficiaries was underestimated when marital status was not considered. Based on the observed difference, risk can be adjusted to improve mortality risk management and ensure the financial soundness of pension funds.

This study is limited by the available age ranges in the life table. Since mortality rates by marital status were available only up to age 84 , the term of annuity was confined to 30 years. Future studies will be able to calculate the value of annuity payments for whole life when sufficient experience data for advanced age groups become available. Future studies could also examine the behavior of mortality difference patterns among the advanced age groups. Further, this study used population data for its analysis. However, the degree and pattern of mortality differences by marital status found in this study may not be applicable to a group of people under various specific pension schemes. Especially, mortality difference pattern associated with marital status may differ in experience data of reverse mortgage due to anti-selection. Therefore, future experience studies could examine data drawn from the specific groups under consideration.

This study could be extended to other identified mortality risk factors. If differences in mortality by risk factor can be quantified, the overall risk for a group of policyholders can be evaluated more accurately and be compared with the risk through analyses in which the risk factor is not considered. The risk can then be adjusted based on the difference observed in the comparison. Performing mortality risk analyses based on risk factors requires the construction of a database on mortality associated with various risk factors as well as vital experience studies.

\section{Appendix: Appendix}

Main results obtained using Whittaker-Henderson's graduation method 
Table 1.1: Expected payment periods (consideration of mortality difference)

\begin{tabular}{|c|c|c|c|c|c|}
\hline \multicolumn{2}{|c|}{ Age } & \multicolumn{2}{|c|}{ In State 1-3 } & \multicolumn{2}{|c|}{ In State 1} \\
\hline Male & Female & Expected value & Standard deviation & Expected value & Standard deviation \\
\hline 55 & 52 & 29.20 & 2.53 & 23.19 & 7.63 \\
\hline 55 & 53 & 29.11 & 2.65 & 23.05 & 7.65 \\
\hline 55 & 54 & 29.00 & 2.78 & 22.89 & 7.67 \\
\hline 55 & 55 & 28.88 & 2.91 & 22.71 & 7.68 \\
\hline 54 & 55 & 28.97 & 2.80 & 23.12 & 7.60 \\
\hline 53 & 55 & 29.06 & 2.69 & 23.50 & 7.51 \\
\hline 52 & 55 & 29.14 & 2.59 & 23.85 & 7.42 \\
\hline
\end{tabular}

Table 1.2: Expected payment periods (without consideration of mortality difference)

\begin{tabular}{|c|c|c|c|c|c|}
\hline \multicolumn{2}{|c|}{ Age } & \multicolumn{2}{|c|}{ In State 1-3 } & \multicolumn{2}{|c|}{$\begin{array}{ll}\text { In State } 1 \\
\end{array}$} \\
\hline Male & Female & Expected value & Standard deviation & Expected value & Standard deviation \\
\hline 55 & 52 & 29.17 & 2.59 & 22.45 & 8.02 \\
\hline 55 & 53 & 29.07 & 2.72 & 22.29 & 8.03 \\
\hline 55 & 54 & 28.95 & 2.85 & 22.12 & 8.03 \\
\hline 55 & 55 & 28.83 & 2.99 & 21.93 & 8.03 \\
\hline 54 & 55 & 28.91 & 2.89 & 22.32 & 7.98 \\
\hline 53 & 55 & 29.00 & 2.79 & 22.69 & 7.92 \\
\hline 52 & 55 & 29.08 & 2.69 & 23.02 & 7.86 \\
\hline
\end{tabular}

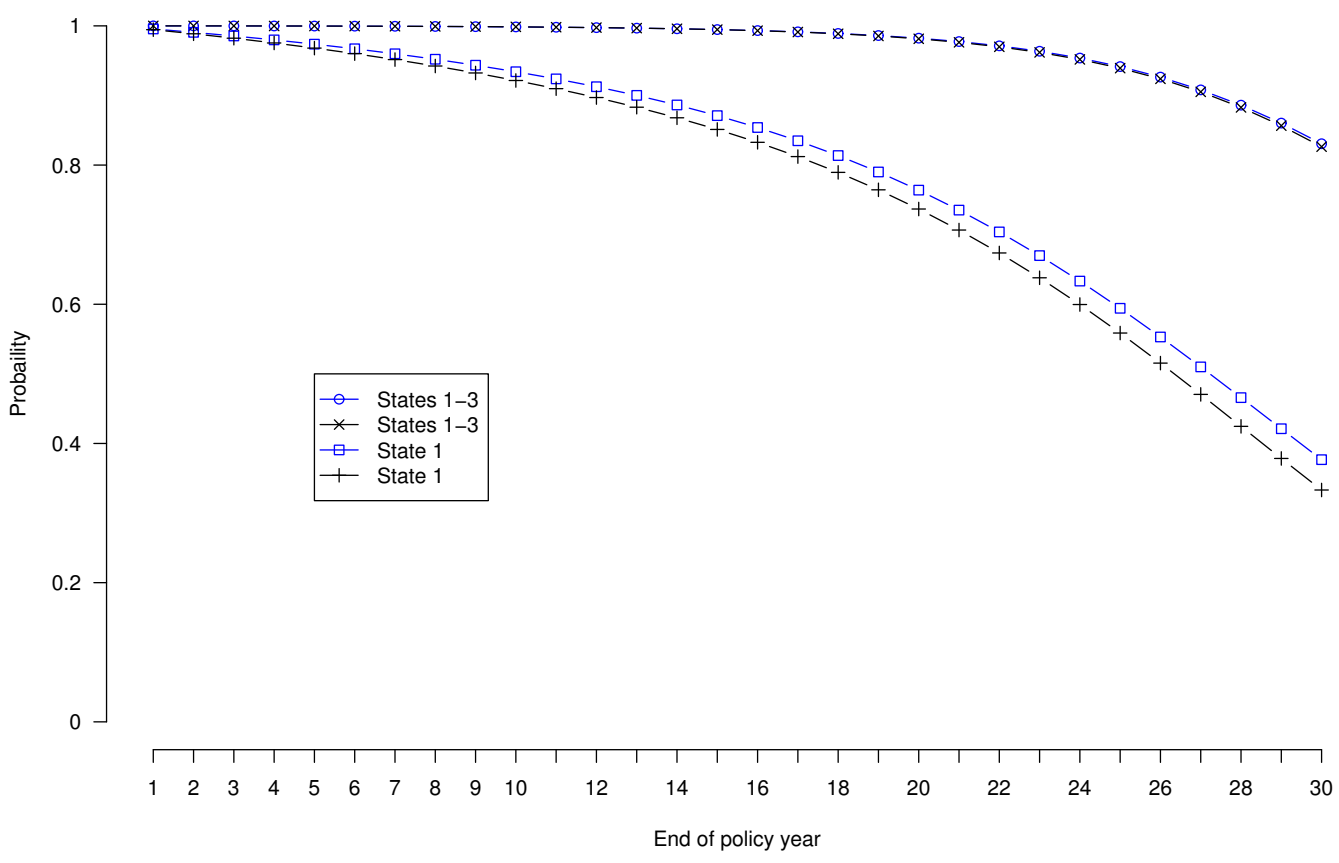

Figure 1.1: Probability of being in certain state(s) at the end of each policy year. 
Table 1.3: Expected payment periods (without consideration of mortality difference)

\begin{tabular}{ccccccc}
\hline \hline Interest rate & Annuitant & Spouse & EPV & Standard deviation & EPV & Standard deviation \\
\hline \multirow{6}{*}{$2 \%$} & $55(\mathrm{M})$ & $52(\mathrm{~F})$ & 21.2968 & 2.3211 & 21.1305 & 2.4606 \\
& $55(\mathrm{M})$ & $53(\mathrm{~F})$ & 21.2677 & 2.3604 & 21.1009 & 2.5004 \\
& $55(\mathrm{M})$ & $54(\mathrm{~F})$ & 21.2347 & 2.4039 & 21.0672 & 2.5447 \\
& $55(\mathrm{M})$ & $55(\mathrm{~F})$ & 21.1975 & 2.4518 & 21.0293 & 2.5936 \\
& $55(\mathrm{~F})$ & $52(\mathrm{M})$ & 21.9795 & 1.9927 & 21.8887 & 2.0741 \\
& $55(\mathrm{~F})$ & $53(\mathrm{M})$ & 21.9542 & 2.0376 & 21.8652 & 2.1172 \\
& $55(\mathrm{~F})$ & $54(\mathrm{M})$ & 21.9269 & 2.0854 & 21.8399 & 2.1628 \\
& $55(\mathrm{~F})$ & $55(\mathrm{M})$ & 21.8976 & 2.1359 & 21.8128 & 2.2109 \\
\hline & $55(\mathrm{M})$ & $52(\mathrm{~F})$ & 18.9372 & 1.9280 & 18.7966 & 2.0532 \\
& $55(\mathrm{M})$ & $53(\mathrm{~F})$ & 18.9144 & 1.9588 & 18.7734 & 2.0844 \\
& $55(\mathrm{M})$ & $54(\mathrm{~F})$ & 18.8885 & 1.9930 & 18.7471 & 2.1192 \\
& $55(\mathrm{M})$ & $55(\mathrm{~F})$ & 18.8593 & 2.0308 & 18.7173 & 2.1577 \\
& $55(\mathrm{~F})$ & $52(\mathrm{M})$ & 19.4958 & 1.6345 & 19.4222 & 1.7037 \\
& $55(\mathrm{~F})$ & $53(\mathrm{M})$ & 19.4759 & 1.6702 & 19.4037 & 1.7380 \\
& $55(\mathrm{~F})$ & $54(\mathrm{M})$ & 19.4545 & 1.7082 & 19.3838 & 1.7744 \\
& $55(\mathrm{~F})$ & $55(\mathrm{M})$ & 19.4315 & 1.7485 & 19.3625 & 1.8128 \\
\hline \hline & $55(\mathrm{M})$ & $52(\mathrm{~F})$ & 16.9661 & 1.6143 & 16.8466 & 1.7273 \\
& $55(\mathrm{M})$ & $53(\mathrm{~F})$ & 16.9481 & 1.6386 & 16.8283 & 1.7519 \\
& $55(\mathrm{M})$ & $54(\mathrm{~F})$ & 16.9278 & 1.6656 & 16.8075 & 1.7793 \\
& $55(\mathrm{M})$ & $55(\mathrm{~F})$ & 16.9048 & 1.6955 & 16.7841 & 1.8097 \\
& $55(\mathrm{~F})$ & $52(\mathrm{M})$ & 17.4259 & 1.3511 & 17.3658 & 1.4103 \\
& $55(\mathrm{~F})$ & $53(\mathrm{M})$ & 17.4102 & 1.3795 & 17.3513 & 1.4377 \\
& $55(\mathrm{~F})$ & $54(\mathrm{M})$ & 17.3933 & 1.4099 & 17.3356 & 1.4669 \\
& $55(\mathrm{~F})$ & $55(\mathrm{M})$ & 17.3752 & 1.4422 & 17.3187 & 1.4978 \\
\hline
\end{tabular}

\section{References}

Alaminos E and Ayuso M (2019). "Marital status, gender, mortality and pensions : The disadvantages of being single in old age", Revista Espanola de Investigaciones Sociologicas, 165, 3-24.

Brockmann H and Klein T (2004). "Love and death in Germany: The marital biography and its effect on mortality", Journal of Marriage and Family, 66, 567-581.

Brown RL and McDaid J (2003). "Factors affecting retirement mortality", North American Actuarial Journal, 7, 24-43.

Bulanda JR, Brown S and Yamashita T (2016). "Marital quality, marital dissolution, and mortality risk during the later life course", Social Science and Medicine, 165, 119-127.

Dickson DCM, Hardy MR, and Waters HR (2020). "Actuarial Mathematics for Life Contingent Risks", Cambridge University Press, New York.

Frees EW, Jacques C and Emiliano V (1996). "Annuity valuation with dependent mortality", Journal of Risk and Insurance, 63, 229-261.

Gomez SL, Hurley S, Canchola AJ, Keegan THM, Cheng I, Murphy JD, Clarke CA and Glaser SL (2016). "Effects of marital status and economic resources on survival after cancer: A populationbased study", Cancer, 122, 1618-1625.

Gove WR (1973). "Sex, Marital Status, and Mortality", American Journal of Sociology, 79, 45-67.

Hedel KV, Lenthe FJV, Avendano M, et al. (2015). "Marital status, labour force activity and mortality: A study in the USA and six European countries", Scandinavian Journal of Public Health, 43, $469-480$.

Hu Y and Goldman N (1990). "Mortality differentials by marital status: An international compari- 
son", Demography, 27, 233-250.

Jia $\mathrm{H}$ and Lubetkin EI (2020). "Life expectancy and active life expectancy by marital status among older U.S. adults: Results from the U.S. medicare health outcome survey (HOS)", SSM-Population Health, 12, 100642.

Kposowa AJ (2000). "Marital Status and Suicide in the National Longitudinal Mortality Study", Journal of Epidemiology and Community Health, 54, 254-261.

Kwon HS (2015). "Consideration of Marital Status in a Mortality Model and its Application for Mortality Risk Management”, Asia Pacific Journal of Risk and Insurance, 10, 193-216.

Kwon HS and Jones BL (2006). "The Impact of the Determinants of Mortality on Life Insurance and Annuities", Insurance: Mathematics and Economics, 38, 271-288.

Kwon HS and Kim JE (2013). "Designing a Life Actuarial Model with Reflection of Mortality Differential by Marital Status", Journal of the Korean Data and Information Science Society, 24, 571-584.

Lee SY (2012). "Mortality Differential by Marital Status", Journal of the Korean Official Statistics, 17, 53-68.

Lillard LA and Panis CW (1996). "Marital Status and Mortality: The Role of Health", Demography, 33, 313-327.

Lowrie WB (1982). "An Extension of the Whittaker-Henderson Method of Graduation", Transactions of Society of Actuaries, 34, 329-368.

Martinez ME, Anderson K, Murphy JD, et al. (2016). "Differences in marital status and mortality by race/ethnicity and nativity among California cancer patients", Cancer, 122, 1570-1578.

Murphy M, Kalogirou S, and Grundy E (2007). "The Increase in Marital Status Differences in Mortality up to the Oldest Age in Seven European Countries, 1990-99”, Population Studies, 61, 287-298.

Park SK, Lee CK, and Kim H (2018). "Suicide mortality and marital status for specific ages, genders, and education levels in South Korea: Using a virtually individualized dataset from national aggregate data", Journal of Affective Disorders, 237, 87-93.

Park YS, Park SK, Choi BS, and Kim KH (2009). "A comparison of probability of death result using beers's interpolation coefficient and Greville's formula", Journal of the Korean Data Analysis Society, 11, 97-110.

Pechholdova M and Samanova G (2013). "Mortality by marital status in a rapidly changing society: Evidence from the Czech Republic", Demographic Research, 29, 307-322.

Ramezankhani A, Azizi F, and Hadaegh F (2019). "Associations of marital status with diabetes, hypertension, cardiovascular disease and all-cause mortality: A long term follow-up study", PLoS ONE, 14, e0215593.

Smith KR and Waitzman N (1994). "Double jeopardy: interaction effects of marital and poverty status on the risk of mortality", Demography, 31, 487-507.

Trovato F and Lauris G (1989). "Marital Status and Mortality in Canada: 1951-1981”, Journal of Marriage and Family, 51, 907-922.

Whisman MA, Gilmour AL, and Salinger JM (2018). "Marital satisfaction and mortality in the United States adult population", Health Psychology, 37, 1041-1044. 